\title{
"QUE AQUÍ NO PASA NADA QUE PURAMENTE TODO": CHILLÁN EN LA POESÍA DE NICANOR PARRA
}

\author{
"NOTHING EVER HAPPENS HERE, BUT ONLY \\ EVERYTHING": NICANOR PARRA'S POETRY \\ FEATURING CHILLAN TRADITIONS
}

\section{JUAN GABRIEL ARAYA GRANDÓN*}

\section{RESUMEN}

Es difícil imaginar la poesía de Parra sin referencia alguna a Chillán, ciudad en la que vivió su niñez y adolescencia, avistada desde la madurez como el bizco hablante lírico de sus poemas. Estimamos que Chillán imanta la antipoesía parriana, desorientando la brújula del lenguaje. Revisamos la presencia textual de Chillán en la producción poética de Nicanor Parra, con especial énfasis en los recursos paródicos, utópicos, irónicos y humorísticos.

Palabras clave: Nicanor Parra, antipoesía, Chillán, aldea.

\section{ABSTRACT}

It is difficult to imagine Parra's poetry without some reference to Chillan, the city in which he lived his childhood and adolescence and seen from his maturity as the cockeyed lyrical voice of his poems. We think that Chillán is a magnet in Parra's antipoetry, disorienting the compass of his language. We look at the textual presence of Chillan in the poetic production of Nicanor Parra with special emphasis on parodic, utopic, ironic and humoristic resources.

Key words: Nicanor Parra, antipoetry, Chillán, town.

Recibido: 20.03.14. Aceptado: 04.06.14.

* Posgrado en Literatura Latinoamericana por el Instituto Caro y Cuervo, Colombia. Profesor Universidad del Bío-Bío. Chillán, Chile.Correo: jaraya@ubiobio.cl 
$\mathrm{D}$ E ACUERDO a GASTÓN BACHELARD el hombre antes de ser lanzado al mundo es "depositado en la cuna de la casa" (1965: 39). Dicho acto originario tiene la virtud de desencadenar en el individuo uno de los mayores poderes que posee: su capacidad evocativa. La casa alberga el sueño, alberga tiempo comprimido (40). Al leer a Bachelard pensamos en Parra y su relación con Chillán. La posesión de ese territorio es condición esencial del poetizar de Nicanor Parra. En adelante, nos guía el afán de revisar cómo ese acto originario que describe el filósofo francés contribuye a explicar la integración del sujeto parriano a un reino de la memoria, a las huellas de su aldea.

Apostamos que para quienes hayan leído la poesía de Nicanor es difícil imaginar que esta pueda desprenderse de forma definitiva de la cuna primigenia o su primera morada. Deducimos, sin esperar respuesta, que para el sujeto parriano Chillán constituirá para siempre una fuente generadora de imágenes y vivencias a las que recurrirá cuando necesite tomar aliento para crearse nuevos territorios o descomponer los ya creados o vividos.

Hemos puesto de relieve en otro sitio (Araya, 2004; 2008) la heterogeneidad del discurso parriano, sus guiños vanguardistas y su visión posmoderna de la sociedad. Ahora, nos parece importante situar fenomenológicamente la relación entre poemas de Nicanor Parra y su territorio originario. Para cumplir con este objetivo se hace indispensable descubrir, antes que todo, los núcleos vitales que revelan su función de pertenencia o copertenencia a un ámbito o territorio propio, poniendo de relieve los matices que explican los fenómenos de arraigo y sus huellas en la producción literaria de Parra.

Las raíces de la poesía parriana se encuentran en la cuna de la casa. Sin la casa Nicanor sería un sujeto disperso. Y sin duda lo es: energúmeno, profeta, Hamlet, francotirador, bufón, príncipe, cortesano... En todo caso, cualquiera que sea la transformación del sujeto, emergerán reiteradamente en su poesía las marcas indiciales de aquello que el propio hablante denomina "los lugares sagrados", es decir, los espacios de origen, territorios que recorren, ambientan y definen gran parte de los poemas de Parra. A veces estos territorios provincianos envuelven la totalidad del poema, como en el caso del antipoema "El túnel" u "Hombre al agua". En otras, es parcial o sencillamente referencial, tal como en "Yo soy más de La Reina que de La Isla". Se trata, como sugieren Gilles Deleuze y Félix Guattari, de territorios transportables y neumáticos, como "casa de tortuga o concha de crustáceo" (2002: 326). Al igual que cuando Nicanor necesitaba en la década del '30 del siglo pasado de las elevadas aspas del molino de agua de sus vecinos, la familia Garvarino, para orientarse en el pueblo de su infancia, en su producción poética se le hará imprescindible hablar de Chillán. 
Desde Poemas y antipoemas (1954) hasta composiciones de su última inspiración, incluyendo sus papeles inéditos, Parra marca su producción con sus lugares sagrados. Al decir de Bachelard, los espacios amados, defendidos contra fuerzas adversas son espacios imaginados, pero a fuerza de ser vividos. Configuran una topofilia (Bachelard, 1965: 29). Estas instancias poéticas se resuelven en imágenes de espacio feliz, en lugares utópicos, añorados; también se expresa en lugares odiados, contrautópicos y sombríos. Sin embargo, en el común de los casos, son espacios que definen al sujeto en contra de fuerzas adversas que están a punto de vencerlo, o bien, de reducirlo a la impotencia. Los poemas de Nicanor Parra, afirma Andrés Gallardo, son "poemas chilenos o chillanejos y no pueden ser entendidos si no se tiene ello en cuenta" (36). La palabra Chillán, o alguna semejante, actúa como fuerza protectora: imanta al poema con signos positivos, constituyéndose en refugio mítico o en un talismán de buena suerte.

La presencia de la aldea está visible a partir de los primeros juegos poéticos de Nicanor Parra. Allí se encuentran para comprobarlo, los poemas que escribió en las proximidades de la década de los 40. Por ejemplo, en "Epopeya de Chillán" (1939) dirá "Chillán, Chillán existes como una rosa blanca sobre mi corazón húmedo y sin palabras" (Parra, 2006: 666) ${ }^{1}$. El poema, de resonancias míticas, de corte nerudiano -para Andrés Gallardo (2004: 33) "de retórica altisonante, insegura e inmadura"-, representa un espacio de pureza devastado por el sismo de 1939 y que funda una serie de referencias explícitas e implícitas de su pueblo. Técnicamente, el antipoema todavía no existe, aunque preexista un germen de éste en los mismos textos. Estos vestigios del primer Parra permiten establecer los primeros contrastes entre poemas y antipoemas, así como sus puntos de aproximación.

Con todo, no hay que desconocer que su libro inaugural, Cancionero sin nombre $(1937)^{2}$, no parece tener resonancias del valle de nacimiento; más bien, recoge los aires poéticos citadinos que respirara en su etapa santiaguina como estudiante e inspector del Internado Nacional Barros Arana, antes que los ruralizantes vientos de su provincia. Situados en el itinerario

\section{POEMAS I
ATTIP0IMAS}

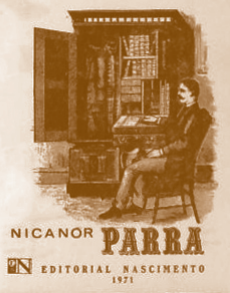

\footnotetext{
${ }^{1}$ El poema fue publicado por primera vez en Ocho nuevos poetas chilenos, Tomás Lago (comp.), Santiago: Universidad de Chile, 1939. El mismo año, apareció en un suplemento literario de la revista SECH, de la Universidad de Chile. También fue publicado en 1960 por Anales de la Universidad de Chile en la sección "Literatura". Las obras completas de 2011 recogen este poema olvidado.

${ }^{2}$ Huelga señalar que el título de esta publicación se encuentra inspirado en un (antipoético) almacén de la Quinta Normal de ese tiempo, llamado "Almacén sin nombre", que regentaba un comerciante italiano llamado Rodolfo Costa Bella.
} 


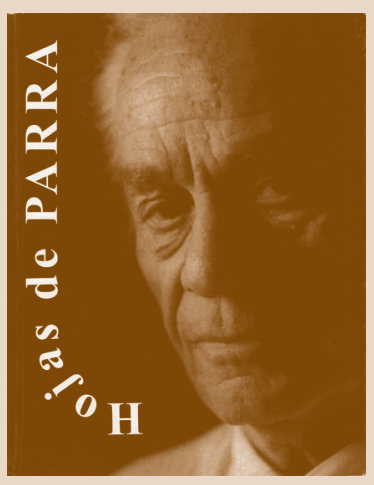

de las publicaciones del autor, es posible destacar los siguientes poemas que tienen, en mayor o menor grado, el carácter de cuna de la casa o referencias a su ciudad: de Poemas y antipoemas (1954), tenemos "Epitafio", "Es olvido", "Hay un día feliz", "Palabras a Tomás Lago", "El túnel”, "Los vicios del mundo moderno", "Soliloquios del individuo"; de La cueca larga (1958)", destacamos "Brindis a lo humano y a lo divino" y el poema homónimo "La cueca larga"; por su parte, en Versos de salón (1962) encontramos el poema "Hombre al agua"; en Canciones rusas (1976) tenemos el texto "Malos recuerdos"; en Discursos (1962)4, "Salutación a Neruda"; en La camisa de fuer$z a$ (1969) es posible observar las referencias en "Discurso del buen ladrón" y "Yo pecador"; en Otros poemas (1969) se encuentran "Los dos compadres" y "Defensa de Violeta Parra"; de Hojas de Parra (1985) rescatamos "Galería de personajes"; y finalmente del "Especial Parra" del semanario The Clinic, "Coplas de San Fabián", que poetiza su lugar de nacimiento.

Si bien es cierto, en Poemas y antipoemas se pueden distinguir claramente tres secciones precisas, la ambientación, en general, corresponde a una atmósfera que se surte de la provincia. El carácter marginal o excéntrico de la poesía parriana es destacado por Niall Binns en su "Introducción" a las Obras completas de Parra. En la sección "Prehistoria de un antipoeta", el crítico inglés señala que Parra es "un francotirador identificado desde la raíz con la pobreza -con la miseria, mejor dicho- de su infancia en los suburbios de Chillán" (2006: XXXVI). Pese a que muchos de los poemas del libro de 1954 se escribieron en Oxford, la jerga utilizada es disruptiva y auténticamente chillaneja: una mezcla de lengua barrial y lírica popular. Tanto en sus poemas expresionistas como en los sentimentales, metafísicos, como en los poemas rupturistas o patafísicos que conforman los antipoemas, es posible advertir un tono o modo de decir irónico y desmitificador que cuestiona y erosiona al discurso propio: un acercamiento poderoso a los límites mismos del lenguaje de la poesía chilena, hispanoamericana y universal. Por el borde de ese límite el sujeto traza, al decir del experto parriano Iván Carrasco,

\footnotetext{
${ }^{3}$ La edición de 1958 cuenta con ilustraciones del pintor Nemesio Antúnez. Una versión posterior publicó la Editorial Universitaria de Buenos Aires de 1964, con prólogo eintroducción de Margarita Aguirre y de Juan Agustín Palazuelos.

${ }^{4}$ Con motivo de la incorporación de Pablo Neruda a la Facultad de Filosofía y Educación de la Universidad de Chile, en calidad de Miembro Académico, Parra pronunció el discurso de incorporación. Ambos discursos: el de Neruda y el de Parra fueron publicados en este volumen.
} 
su propio camino textual, no ser un "copión", sino un creador auténtico. La asunción de este método se fundamenta en el origen popular de Nicanor Parra [...] "Los que venimos del barrio Estación -de Chillánreaccionamos distinto a los otros" [...] El carácter popular de Parra no es pose snob, ni determinación política o ideológica, sino auténtico modo de vivir (1990: 126).

Breves notas biográficas, familiares, romances juveniles tronchados por la muerte, aldeas detenidas en el tiempo, imágenes veloces de la infancia sostenidas en melancólicas fugas mentales, borrones del tiempo y titubeos del espíritu configuran y vertebran poemas como "Epitafio", "Es olvido" y "Hay un día feliz". Son poemas utopizantes, de palabra suave, introspectivos y exploratorios, aplicables, en suma, a cualquier territorio. Como su nombre lo indica -aunque con Parra el valor de lo referencial pierde espesor, o, dicho más brevemente, "con Parra nunca se sabe"- "Epitafio" está dedicado al camposanto, aquel espacio tan reiterado en su poesía, cuya imagen topofílica se encuentra en el Cementerio Municipal del barrio Villa Alegre, sector ultraestración de Chillán, por cuyas calles polvorientas y sin asfalto caminó Nicanor y sus hermanos, hijos de un profesor primario alborotador y de una modista. "Hijo mayor de profesor primario / y de una modista de trastienda" (Parra, 2006: 29). En estos versos Parra nos remite a su genealogía para definir su persona al final del poema como " $i U n$ embutido de ángel y bestia!”. Al definirse contradictoriamente, ya nos está mostrando el anverso y el reverso, las dos caras de Jano que tendrá su propia poesía. Precisamente, la parte angélica del poeta será la que determine los dos logrados poemas que se titulan "Es olvido" y "Hay un día feliz". El primer poema es la representación de uno de sus idilios de liceano, evocado con la nostalgia fantasiosa con que un hombre escribe, en la madurez, el diario de vida de sus amores juveniles pueblerinos. El poema "Hay un día feliz" es el viaje que el poeta emprende hacia el país de su infancia. Un viaje en la búsqueda "de un núcleo de infancia, de una infancia inmóvil, pero siempre viva, fuera de la historia, escondida de los demás, disfrazada cuando la contamos, pero que solo podrá ser real en esos instantes de iluminación, es decir, en los instantes de su existencia poética" (1965: 1961), tal como lo afirma Bachelard, casi pensando en el poema de referencia.

"Hay un día feliz" es el recorrido de ensueño a El País de Nunca Jamás. Es la región legendaria que presenció los "hechos memorables" de su primera juventud. Es la recreación del instante y de la eternidad que, en virtud de la evocación poética, se fusionan en un hablante que busca el tiempo perdido en su vieja aldea. A la vez, "Hay un día feliz" es la construcción 
mítica de la infancia y de su territorio geográfico y existencial. Hay, claro, la superación irreal o imaginaria y la sublimación de los dolores o de los sucesos adversos, mitigados por el tiempo. El poema constituye, a la postre, la visión serena de un período de vida, visto desde la madurez.

En otro nivel de análisis, como ha señalado Mario Rodríguez ${ }^{5}$, en el poema nos encontramos "con la dignidad melancólica del príncipe", tal como en "El hombre imaginario". El príncipe "se las ingenia para colocar una frase melancólica", a diferencia del "loco discurso de la negación y la revuelta, la risa y el humor destructivo del bufón" (1992: 2). En todo caso, cualquiera que sea la causa definitiva -si es que existe algo así- este poema representa una de las más evidentes manifestaciones de la presencia del pueblo originario en su poesía. Si alguna vez Nicanor Parra declaró que el molino de los Garvarino del barrio Villa Alegre era su punto principal de referencia, este poema lo confirma: "Pasé frente a la rueda del molino" (2006: 13). El peregrinaje de este flâneur mitificador tiene por objeto resucitar un mundo borrado por el tiempo y sumergido en "una blanca tempestad de arena" (14).

"Palabras a Tomás Lago", "El túnel", "Los vicios del mundo moderno" y "Soliloquio del individuo", contienen, también, elementos que configuran o remiten al valle de origen. "Palabras a Tomás Lago"6 tematiza lugares y espacios de Chillán, concretamente un ya desaparecido restaurante de la Avenida Libertad. El asunto del texto remite a una conversación sostenida entre el sujeto y su amigo antes del terremoto de enero de $1939^{7}$. Como se puede apreciar, la poesía parriana se encuentra llena de registros de aquella época en la que Nicanor aún se hallaba férreamente vinculado a su provincia. Uno de los ejemplos que nos permite afirmar lo anterior es el poema "El túnel". Según Nicanor, este es un ejemplo de texto cuyo tema obedece a una experiencia traumática transcurrida en su juventud. La anécdota que vivifica la composición nos ha sido narrada por el poeta y tiene que ver con una cita de amor que debió haber resultado exitosa, pero que se malogró: por ese tiempo, el centenario poeta había contratado un coche para visitar a la joven Maruja Labbé. La idea era impresionar a la señorita, sin embargo, aquel viaje, que se inició en Chillán Viejo, resultó ser una odisea a partir del

\footnotetext{
${ }^{5}$ Coincidentemente con este tratamiento chillanejo, el profesor de la Universidad de Concepción Mario Rodríguez publicó la reseña a la que nos referimos en el diario La Discusión de Chillán.

${ }^{6}$ Tomás Lago (Chillán, 1903 - Santiago, 1975). Escritor de relevancia en el plano nacional. Amigo de otros grandes escritores como Neruda y Parra. Autor de El huaso (1953).

${ }^{7}$ Además, trata de la misma época en que Nicanor publicaba en el diario chillanejo La Discusión un artículo sobre Pablo Neruda, titulado "Hablemos de Pablo".
} 
momento en que unas ancianas, una de ellas paralítica, abordaron sorpresivamente el carruaje, exigiendo que llevaran a la enferma al hospital. Al final del viaje el poeta tiene que bajar en brazos a una de estas señoras, quedando en una situación muy poco airosa frente a su enamorada y a la familia de ésta que lo esperaban en un paradero.

Al leer el antipoema resulta evidente que dicha anécdota no se halla transcripta al pie de la letra. El proceso de transformación de la realidad, propio del arte, opera con total éxito en la pieza parriana. Esas "tres ancianas histéricas" de Chillán Viejo motivan una situación de trascendencia mayor, en la que el hablante da cuenta de la asfixia de un mundo oprobioso que le acecha y que lo mortifica, sin que él se entere cabalmente de las causas que lo provocan. Desde la perspectiva anterior, el poema resulta ser la reescritura perversa de la aldea idílica, detenida en el tiempo y que ha poetizado en "Hay un día feliz". A través de la lectura del texto, nos damos cuenta de que el sujeto, incluso, tiene que abandonar el mundo de la universidad y los encantos de la vida galante, para "satisfacer los caprichos de tres ancianas histéricas / llenas de toda clase de problemas personales" (46). De este modo nos enteramos también de que el porvenir es poco prometedor para el sujeto condenado a vivir cuatro años en un verdadero túnel: "cuatro años de martirio constante".

Si contrastamos el antipoema "El túnel" con los poemas "Es olvido" y "Hay un día feliz", deberíamos percatarnos de la diferencia que existe entre un mundo evocado míticamente y el mismo mundo, evocado desde la distancia, desde lo degradado, lo grotesco y ominoso. El hablante registra en los poemas iniciales la sublimidad de su mundo, sin embargo, ésta se transformará en aberración, prosaísmo y sarcasmo: es decir, entrará en la órbita caricaturesca del antipoema. Este cambio representa una actualización de relaciones entre el mundo real y el imaginado, que permite que el sujeto se convierta en otro u otros: el cortesano se transforma en una víctima que grita su disconformidad. En efecto, esta disconformidad con las categorías literarias canónicas lo empuja a dibujar una caricatura del "hablante lírico", un corazón con patas. Estimamos que el punto de vista anterior puede servir, por otra parte, para clarificar el paso del poema lírico parriano a lo que denominamos antipoema de desarrollo. Marlene Gottlieb (1977) lo llama "poema-enumeración”. Entre ellos tenemos el poema "Galería de personajes (Alrededores de Chillán, año 1927)" de Hojas de Parra (1985). Es una lista de personajes chillanejos con quien Parra convivió. El texto tiene un tono desacralizador, humorístico. Todos los personajes son nombrados por su apodo. El ejercicio evocativo compromete la interpretación del lector, pues 
la mayoría de los apodos se le presentan como enunciados a interpretar: "El perejil sin hojas / El culebrón / El cebollino sin Huano [... / La tuerca / La Acabo de Mundo" (Parra, 2006: 260).

En dos antipoemas fundamentales de su producción, Parra se refiere a su antiguo lar: "Los vicios del mundo moderno" y "Soliloquio del individuo". Ambos tematizan las más profundas preocupaciones existenciales, culturales y sociales de Parra. Es curioso cómo en el primero se inscriben los terremotos en oposición a la cultura: "Reconozco que un terremoto bien concebido / Puede acabar en algunos segundos con una ciudad rica en tradiciones" (55). Si establecemos un paralelo con otras obras de Parra en las que se trate el mismo motivo, no habría duda de que en "Los vicios del mundo moderno" se privilegia la expresión antipoética del terremoto de Chillán de 1939 y no la lírica, representada en el bello poema "La mano del joven muerto", publicado por primera vez en $1942^{8}$. Esta confrontación, a la vez, nos permite apreciar las dos formas del poetizar parriano sobre un mismo fenómeno. La gran poesía chilena siempre ha dedicado algunos versos a los cataclismos terrestres: tenemos el ejemplo de Huidobro, Neruda y de Rokha. En esta tradición se inscribe Parra, tanto desde la melancolía como desde la posición del bufón.

"Soliloquio del individuo" tal vez sea la pieza capital de este libro. Coincidimos en la apreciación que entrega el crítico norteamericano René de Costa: "En unos ciento veinticuatro apretados versos, Parra repasa la historia de la humanidad, desde sus comienzos en la edad de piedra hasta el momento actual, la edad de la tecnología, en que -como por generación espontánea- 'empezaron a aparecer los primeros automóviles', para concluir, con indiferencia, que 'la vida no tiene sentido"' (1988: 39). Este verdadero poema antropológico tiene como sentido y fundamento la búsqueda del hombre y del ser. En él se reproduce el rehallazgo de la roca fundamental que le sirvió de primer hogar. Parra, literalmente, regresa una vez más a su morada. En efecto, el sujeto, después de reinstalarse en todos los tiempos de la historia y de ejercer los diversos oficios del hombre, en sus diversas etapas, llega a la conclusión siguiente: "Mejor es tal vez que vuelva a ese valle, / A esa roca que me sirvió de hogar" (Parra, 2006: 64). En relación con Poemas y antipoemas, postulamos la hipótesis de que el libro recepciona nítidamente la atracción que en el poeta ejerce la cuna natal, constituyéndose ésta y sus equivalentes, en un polo que imanta el registro poético del autor hacia su infancia y juventud, simbolizados en la roca del origen.

\footnotetext{
${ }^{8}$ En la antología Tres poetas chilenos, preparada por Tomás Lago.
} 
En el libro La cueca larga (1957), Nicanor Parra recoge los aires folclóricos de la tradición popular. Por una parte, se inspira en la poesía oral del pueblo; por la otra, recoge la propia tradición familiar. Es necesario tener en cuenta que tanto su padre como sus hermanos, entre ellos la propia Violeta, sobrinos y nietos, cultivaron el verso popular, haciéndose acompañar por la guitarra o el guitarrón de catorce cuerdas. Con este libro, Parra no hace otra cosa sino reinsertarse con propiedad y calidad en el medio cultural del cual procede. "Brindis (a lo humano y a lo divino)" es un poema dionisíaco que recorre toda la geografía chilena con una copa de vino en mano. Existe en el poema un optimismo vital en función del goce de la vida y de los sentidos. Una clave del poema está dada por el verso " ¿No ve que soy de Chillán?” (2006: 74), expresión que justifica, en el fondo, su manera de ser y la forma de su poetizar.

Consideramos que La cueca larga pertenece a la más genuina tradición chilena. De esa tradición que hacía que los cantores entonaran una larga cueca hasta agotar a los atrevidos bailarines. Campean en esta composición tanto la malicia como la gracia de un pueblo que echa sus versos al aire y con ellos su espíritu burlón y pícaro. En el poema, las marcas toponímicas natales quedan registradas claramente. Es así como el marco de referencias de esta poesía está señalado por la presencia de Coihueco, Niblinto, Portezuelo o Nanco.

Nicanor Parra, en su obra posterior, siempre dejará huellas textuales de su aldea natal. Mitifica su pasado, pero al mismo tiempo lo desacraliza por la vía de dos recursos permanentes: la ironía y la autoironía. En el poema "Hombre al agua", de su libro Versos de salón, el sujeto decide partir a "Chillán en bicicleta” (98). Pues bien, coincidimos, al respecto, con la observación hecha por Mario Rodríguez, quien ha señalado que la representación del viaje "hacia un lugar feliz, en la imagen de un ciclista, no sólo ironiza la situación, sino que establece una violenta incongruencia" (Montes y Rodríguez, 1970: 68). Tanto la alabanza como la ironización de la aldea forman parte del sistema total de un poeta que estructura su mundo a partir de la imagen de un lugar feliz que se desvanece.

\section{REFERENCIAS}

Araya, J. G. (2004). Nicanor en Chillán. Concepción: Universidad del Bío-Bío. (2008). "Nicanor Parra. De la antipoiesis a la ecopoiesis". Estudios Filológicos 43, 9-18.

Bachelard, G. (1965). La poética del espacio. México: FCE.

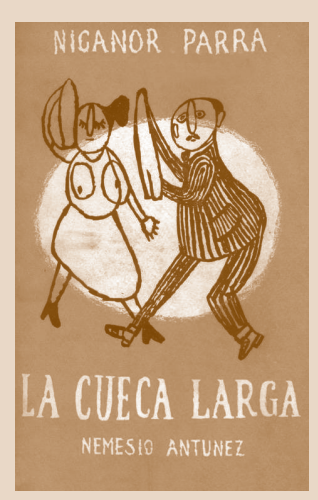


Binns, N. (2006). “Introducción: ¿Por qué leer a Nicanor Parra?”. En Parra, N. Obras completas \& algo + (1935-1972). Barcelona: Galaxia Gutenberg. XXIX-LXXVI.

De Costa, R. (1988). “Introducción”. En Parra, N. Poemas y antipoemas (pp. 9-40). Madrid: Cátedra.

Deleuze, G. y Guattari, F. (2002). Mil mesetas: capitalismo y esquizofrenia. Valencia: Pre-textos.

Carrasco, I. (1990). Nicanor Parra: La escritura antipoética. Santiago: Universitaria.

Gallardo, A. (2004). "Nicanor Parra en el territorio del lenguaje”. Acta Literaria 29, 33-45.

Gottlieb, M. (1977). La poesía de Nicanor Parra. No se termina nunca de nacer. Madrid: Playor.

Montes, H. y Rodríguez, M. (1970). Nicanor Parra y la poesía de lo cotidiano. Santiago: Editorial del Pacífico.

Parra, N. (1937). Cancionero sin nombre. Santiago: Nascimento.

(2006). Obras completas \& algo + (1935-1972). Barcelona: Galaxia Gutenberg.

(2011). Obras completas \& algo + (1975-2006). Barcelona: Galaxia Gutenberg.

Rodríguez, M. (1992, marzo 22). “Nicanor Parra: Poeta de Ñuble. El príncipe y el bufón”. La Discusión, p. 2.

(1996). Órbita de Nicanor Parra. Concepción: Ediciones Universidad de Concepción. 